\title{
UN CONJUNTO DE PLATA HISPANOAMERICANA EN LA IGLESIA DE SAN BARTOLOME DE CARMONA
}

\author{
por M. ${ }^{\mathrm{a}}$ Jesus Mejias Alvarez
}

Se señalan las dificultades que conlleva el estudio de las piezas de Orfebrería Hispanoamericana, para luego pasar al análisis y descripción de las piezas que se hallan en la iglesia parroquial de San Bartolomé de Carmona, Sevilla. Estas son tres: un copón, un cáliz y un ostensorio. Todas presentan la marca de la ciudad mejicana de Zacatecas. El conjunto se encuentra dentro del estilo que impuso el platero mejicano José María RODALLEGA, activo entre 1772 y 1812 . Además, se aporta el único dato documentado, hasta la fecha, sobre una de las piezas de este conjunto, hallado en el Archivo parroquial de la iglesia de San Bartolomé de Carmona, en el Libro de Cuentas de Fábrica de 1775-1791, Auto de cuentas de 17 de octubre de 1789 .

An outline of the difficulties involved in the study of Latin-American gold and silver-work is followed by an analysis and description of the pieces to be found in the parish church of San Bartolomé in Carmona, Seville. There are three of these: a ciborium, a chalice, and an ostensory. All three bear the hall-mark of the Mexicancity of Zacatecas. The set is in the style of the Mexican silver-smith José María RODALLEGA, who was active between 1772 and 1812 . The article also preents the only documentary information available to date on one of the pieces of this set, from the parish archives of the church of San Bartolomé in Carmona, in the Book of Accounts of fabrication, 1775-91, State of Accounts for October 17 th 1789.

La Orfebrería es uno de los muchos capítulos que quedan pendientes de redacción en el Arte Hispanoamericano. Aún así, no faltan artículos específicos y locales que aborden el tema, así como algunos estudios sistemáticos, ya clásicos, de diversas escuelas ${ }^{1}$.

Este carácter inédito de la Platería Hispanoamericana se debe, principalmente, a las dificultades que conllevan su estudio. Estudio que debe afrontarse desde la problemática de su análisis en dos frentes, como ya ha sugerido

1. Para un mejor conocimiento de la bibliografía existente consultar el artículo de la doctora María Jesús Sanz Serrano, «La Platería Hispanoamericana. Estado de la cuestión», Actas VI Jornadas de Andalucía y América. Sevilla, 1987. 
la doctora Cristina Esteras ${ }^{2}$. El primero de estos sería «el americano» y el segundo lo podríamos llamar «el no americano», dentro del que encuadraríamos el español. Esta metodología de estudio viene provocada por la dispersión en la que se halla en la actualidad la plata labrada hispanoamericana. Al problema de la dispersión se une el de la diferenciación de estilo sobre lo español y lo americano, más problemático durante el siglo XVII, tal como apunta la doctora doña María Jesús Sanz ${ }^{3}$, además de la frecuente ausencia de marcas que avalen la procedencia de las piezas y la falta de documentos que autentifiquen el origen de las mismas.

Una aportación, por nuestra parte, al análisis de la Plateria Hispanoamericana en España es este estudio de las piezas que se hallan en la iglesia parroquial de San Bartolomé de Carmona, Sevilla.

Son tres las piezas que analizaremos, un cáliz, un copón y un ostensorio, o custodia de mano; las tres de factura y decoración semejantes ${ }^{4}$.

El copón, de plata dorada al igual que las dos piezas restantes del juego, mide $279 \mathrm{~mm}$. de altura, $138 \mathrm{~mm}$. de diámetro de base y $126 \mathrm{~mm}$. de diámetro de la copa (figura 1). Posee una base elevada y planta mixtilínea, con pestaña saliente y dos cuerpos diferenciados por un estrangulamiento. El astil es una pieza periforme invertida. La copa es ancha y bulbosa cubierta por una tapadera que se remata con una pequeña cruz de sección romboidal. Toda la pieza presenta decoración de cartelas con rocallas en las bandas del perfil convexo mientras que las cóncavas se dejan lisas (figura 2).

El cáliz de plata sobredorada, con una altura de $250 \mathrm{~mm}$., un diámetro de base de $151 \mathrm{~mm}$. y $95 \mathrm{~mm}$. de diámetro de copa, es semajante en decoración y estructura al copón (figura 3). El pie es también elevado y la planta mixtilínea. El astil balaustral se compone de un nudo periforme y un cuello bulboso que no veíamos en el astil del copón. La copa es troncónica, y se separa de la subcopa, abullonada y con el mismo ornato del pie, no sólo por la desnudez de su decoración sino también por un filete o platillo. Con la técnica del cincelado se decora la pieza a base de cartelas de rocallas y sucintas flores y roleos con la inclusión alternante de espacios longitudinales lisos y decorados.

El ostensorio, al igual que sus dos piezas compañeras, es de plata dorada y mide $687 \mathrm{~mm}$. de altura, posee un diámetro de base de $250 \mathrm{~mm}$., $280 \mathrm{~mm}$. de diámetro del sol expositor y $85 \mathrm{~mm}$. de diámetro de la esfera de cristal del sol (figura 4). La base es elevada y mixtilínea, y descansa sobre cuatro

2. Esteras Martín, Cristina: «Nuevas aportaciones a la Historia de la Platería Andaluza-Americana». Actas de las III Jornadas de Andalucía y América. Sevilla, 1985.

3. Sanz Serrano, María Jesús: «Relaciones entre la Platería española y la americana durante el siglo XVII». Actas de las III Jornadas de Andalucía y América. Sevilla, 1985.

4. Estas piezas fueron reseñadas por J. Hernández Díaz, A. Sancho Corbacho y F. Collantes de Terán, en su «Catálgo Arqueológico y Artístico de la provincia de Sevilla», tomo II (Sevilla, 1943), página 145. No hacen un estudio de las mismas ni llegan a clasificarlas como mejicanas, aunque si describen la marca. 
cabezas angélicas. El astil balaustral se compone de tres piezas, un nudo periforme invertido y dos piezas bulbosas, sobre y debajo del nudo. El sol presenta una caja convexa de la que nacen los rayos, y remata con una cruz.

Las tres piezas van marcadas con el punzón de localidad, además de ofrecer burilada. El punzón consiste en un troquel cuadrangular compuesto por una cabeza de perfil, la cabeza de Hércules con giro a la derecha, y debajo una $\mathrm{Z}$, entre dos columnas timbradas por una corona de cinco puntas (figura 5). Esta marca es la distintiva de la ciudad de Zacatecas, importante centro minero del Virreinato de Nueva España (hoy México) ${ }^{5}$. El marcaje esta incompleto, ya que carece de las marcas del autor, del contraste y del impuesto. Este solo nos da a conocer por tanto su procedencia de Zacatecas pero nos priva de saber quien fue su artista. Tampoco hemos encontrado, hasta el momento, documentos que respalden la autoría de las piezas.

En el Libro de Fábrica de 1775-1791, del Archivo Parroquial de la iglesia de San Bartolomé de Carmona hemos hallado el único dato documentado que, hasta la fecha, existe sobre una de las piezas de este conjunto. Así, en el Auto de Cuentas de 17 de octubre de 1789, del citado libro, se registra:

«Platta y sus aderezos en el tiempo dessta quentta parese de tres resibos de don Josef Adrian Camacho artista plattero dessta ciudad (...) habersele pagado 81 reales por limpiar las crismeras, vazo del santo oleo, tres calices, la corona de la Virgen de la Concepción, concha de baptizar, salero, la cajita para llevar el viatico a los enfermos, componer y arreglar la puerta del viril que vino de Indias, y uno broches $(\ldots) »$.

Este documento no aporta nada nuevo acerca del origen del ostensorio, es más si la pieza no estuviese marcada con el punzón de la localidad de la que procede sólo podríamos determinar su origen hispanoamericano. Para lo que si nos sirve esta referencia documental es para aproximarnos a la fecha de su llegada a Carmona. Si en 1789 José Adrián Camacho ${ }^{6}$ estaba trabajando en ella quiere decir que llegó o ese mismo año o pocos años antes, puesto que el estilo de estas piezas no es anterior a 1770.

La datación cronológica de las piezas no causa ningún problema ya que el modelo de este conjunto sigue la tipología de los cálices y copones desarrollada en la ciudad de México en el último cuarto del siglo XVIII. Este estilo lo

5. Consultar la siguiente bibliografía si se quiere ahondar en la Historia de la ciudad de Zacatecas: Bakewell, P.J.: Silver Mining and Society in Colonial México. Zacatecas 1540-1700. Cambridge, 1971. Arlegui, José: Crónica de la Provincia de N.S.P.S. Francisco Zacatecas. México, 1737. Reimpreso en México en 1851.

6. Artista platero vecino de Carmona y examinado en 1771. Se pueden encontrar más datos sobre este platero en Mejías Alvarez, M. Jesús: «La Orfebrería en la iglesia Prioral de Santa María de Carmona». Tesis de Licenciatura. Inédita. 
impuso y lo divulgó el platero mejicano José María Rodallega, nacido en Guadalajara en 1741, examinado en la ciudad de México en 1772, y activo entre los años 1772 y $1812^{7}$. El modelo se codificó y se extendió con facilidad, encontrándonos piezas similares tanto en todo el Virreinato de Nueva España como en la misma España. De México capital llegó hasta otros centros plateros, como lo prueba las piezas que aquí estudiamos, que de no ser porque ostentan la marca de la ciudad de Zacatecas podrían haberse clasificado como obras realizadas por orfebres de México capital.

En México nos encontramos con ejemplares análogos al conjunto de la iglesia de San Bartolomé de Carmona, como son el cáliz de la Colección Salo Hale $^{8}$ y los cálices del Museo Nacional de la Historia (Maxico) ${ }^{9}$.

En España hallamos también piezas semejantes. Sirvan de referencia el cáliz de la Catedral de Albarracín, Teruel ${ }^{10}$, el cáliz de la parroquia de la Granada de Llerena en Badajoz que difiere sólo en la temática del ornamento ${ }^{11}$. Análogo es también el cáliz de la iglesia parroquial de San Vicente, Martín de Potes (Cantabria), que presenta marcas de la ciudad de México, de Diego González de la Cueva y la marca de la ley ${ }^{12}$. Pero sin duda las piezas más cercanas a las nuestras son el cáliz y el copón de la iglesia parroquial de La Lomba en Cantabria ${ }^{13}$. Si en los casos anteriores el modelo y el estilo eran semejantes, en el caso de las piezas de La Lomba nos encontramos que además presentan la marca de la ciudad de Zacatecas.

Es interesante destacar que las piezas del modelo impuesto por Rodallega distribuidas por el territorio español son en su mayoría cálices, no faltando algún que otro copón como el de la iglesia parroquial de La Lomba o el propio de la Iglesia de San Bartolomé de Carmona, pero lo que hasta ahora no han aparecido son ostensorios. Esto nos lleva a resaltar la importancia de las piezas carmonenses, pues las tres forman un conjunto perfecto en el que la mesura ornamental da paso a una estética basada en los perfiles externos, con los entrantes y salientes de su línea sinuosa.

7. Cfr. ANDERSON, L.: The Art of the Silversmith in Mexico (1519-1936). Vol. I, p. 145. Hacker Art Book. New York, 1975. Fernández, A.; Munoa, R. y Rabasco, J.: Enciclopedia de la Plata Española y Virreinal Americana, Madrid, 1984.

8. Anderson, L.: El arte de la platería en México. México, 1956. Figura 85. Cfr. Esteras Martín, C.: La Orfebreria Hispanoamericana. Siglos XVII-XIX. Madrid, 1986.

9. Obregón, G.: «Corrientes estilísticas en la Orfebrería Mexicana», Artes de México, México, n. ${ }^{\circ}$ 112 (1968). Página 47.

10. Cfr. Esteras Martín, C.: La Orfebrería de Teruel y su Provincia. Siglos XIII al XIX. 2 Vols. Teruel, 1980. Figura 172.

11. Esteras Martín, C.: Plateria Hispanoamericana. Siglos $X V I-X I X$. Exposición Diocesana Badajocense. Badajoz, 1984. Páginas 74 y 75.

12. Véase: Carretero Rebes, S.: Platería Religiosa del Barroco en Cantabria. Ediciones de Librería Estudio. Santander, 1986.

13. Esteras Martín, C.: Orfebrería Hispanoamericana. Siglos XVI-XIX. Madrid, 1986. Página 76, Figuras 33 y 34 . 
Esperemos que todo lo expuesto sirva para dar a conocer mejor estas tres piezas Hispanoamericanas de la iglesia de San Bartolomé de Carmona. Con ello queremos contribuir a la recuperación y al estudio de las piezas de Platería Hispanoamericana en Andalucía. Tarea que nos parece necesaria, y muy oportuna ante la próxima celebración de V Centenario del Descubrimiento de América. 


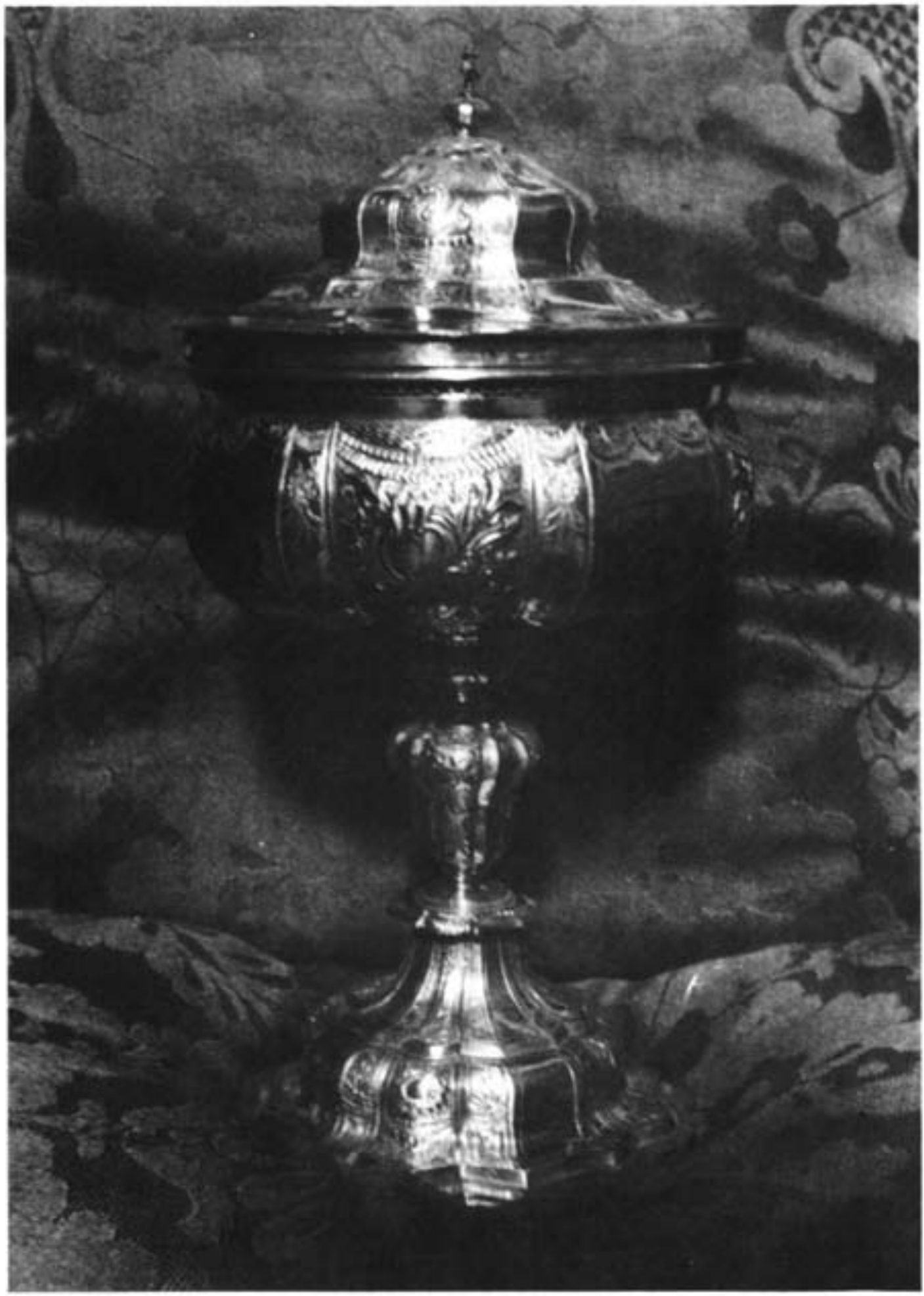

Figura I

Copón. Hacia 1780-85. Parroquia de San Bartolomé. Carmona. 


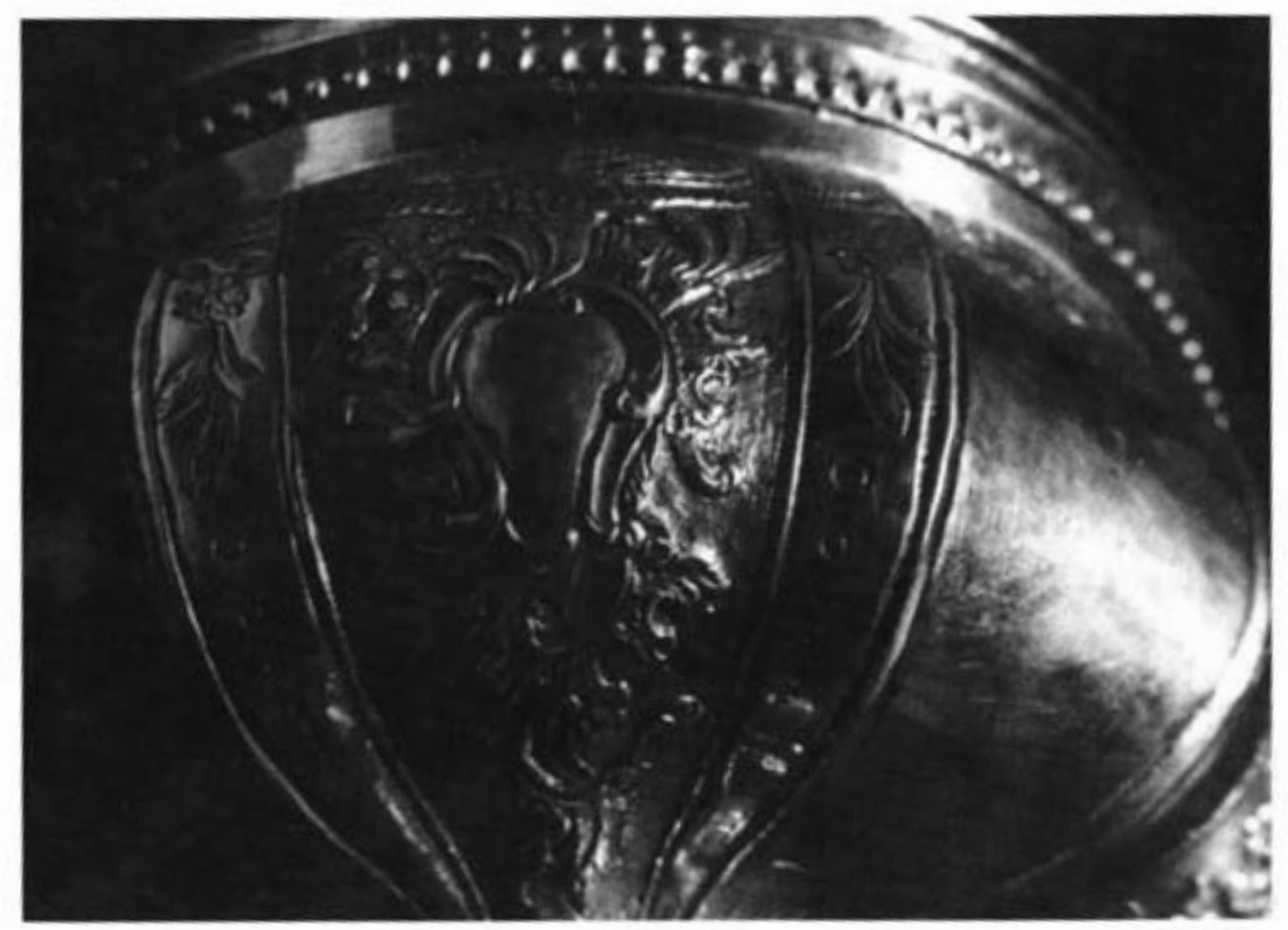

Figura 2

Detalle de la decoracion del copón anterior. 


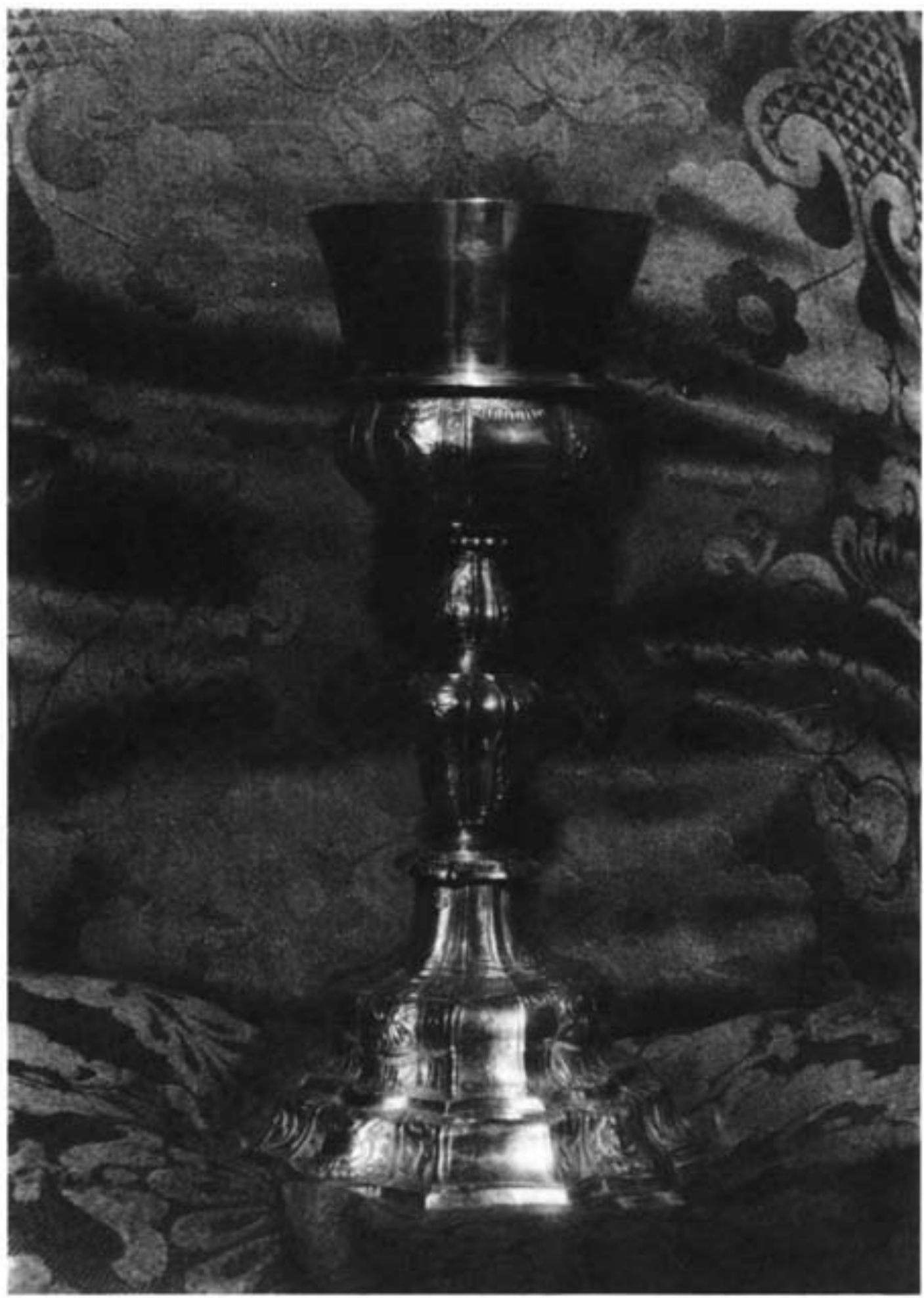

Figura 3

Caliz. Hacia 1780-85. Parroquia de San Bartolomé. Carmona. 


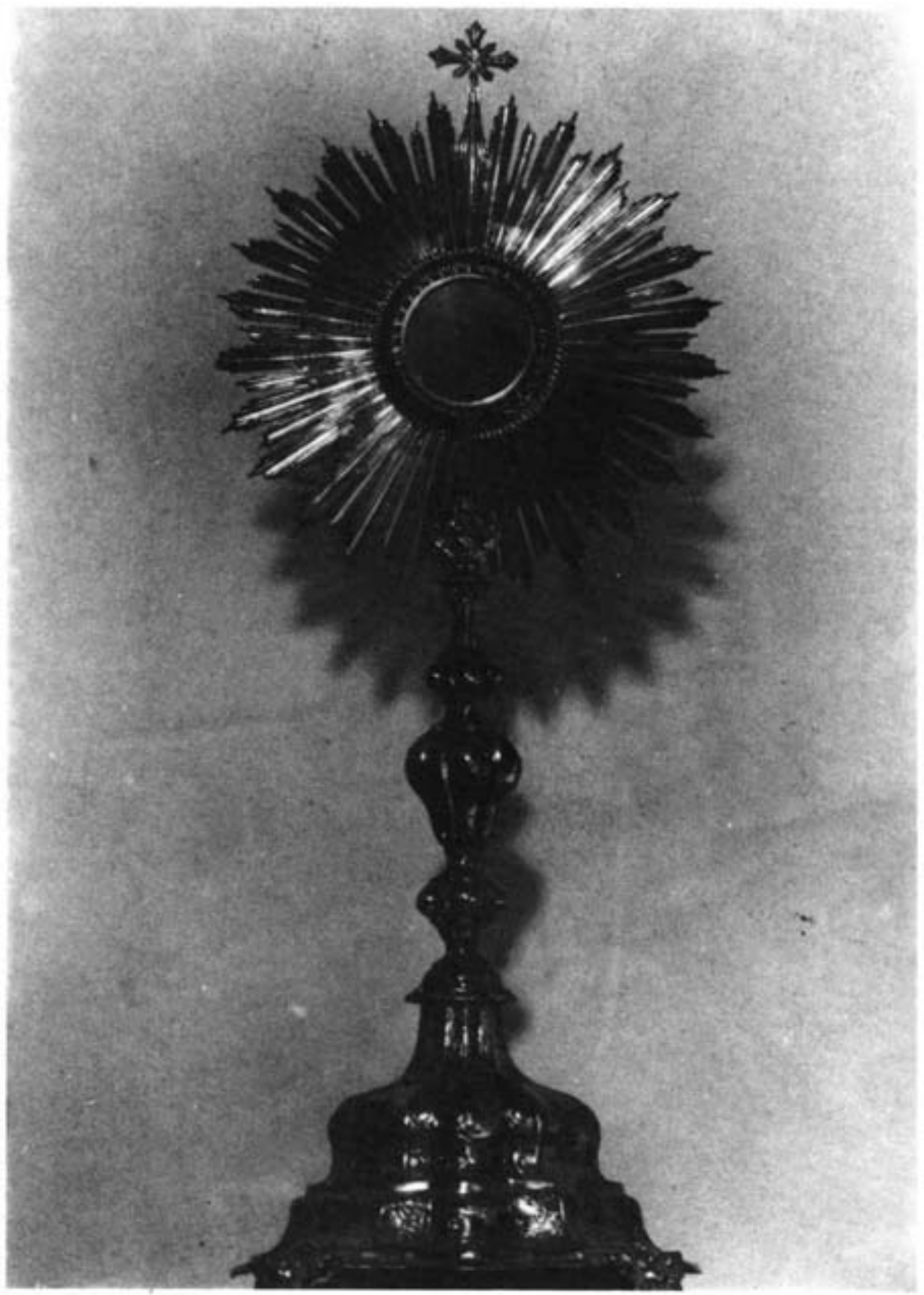

Figura 4

Ostensorio. Hacia 1780-85. Parroquia de San Bartolomé. Carmona. 


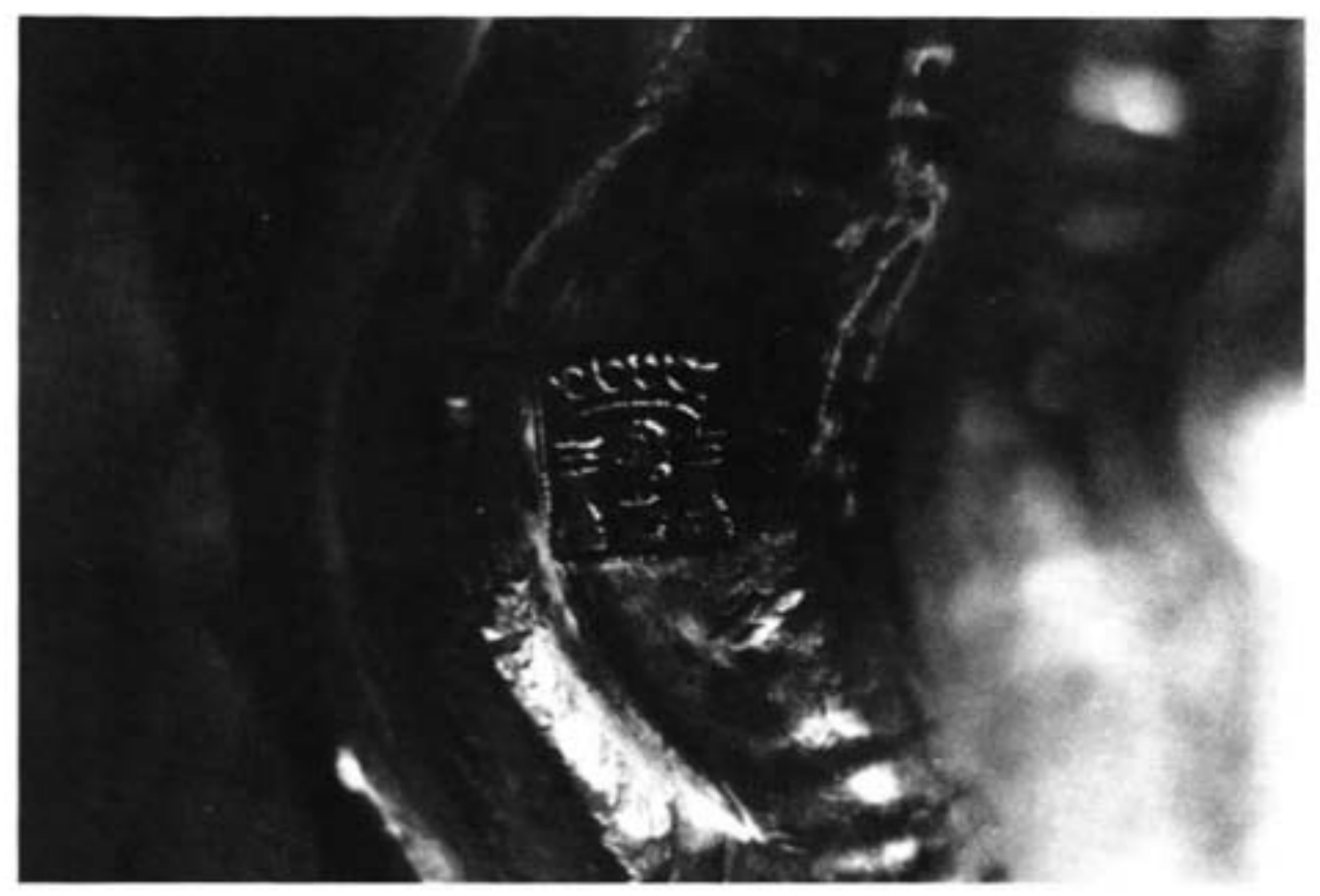

Figura 5

Marca de la ciudad de Zacatecas estampada en el cáliz, copón y ostensorio de la iglesia de San Batolomé. Carmona.

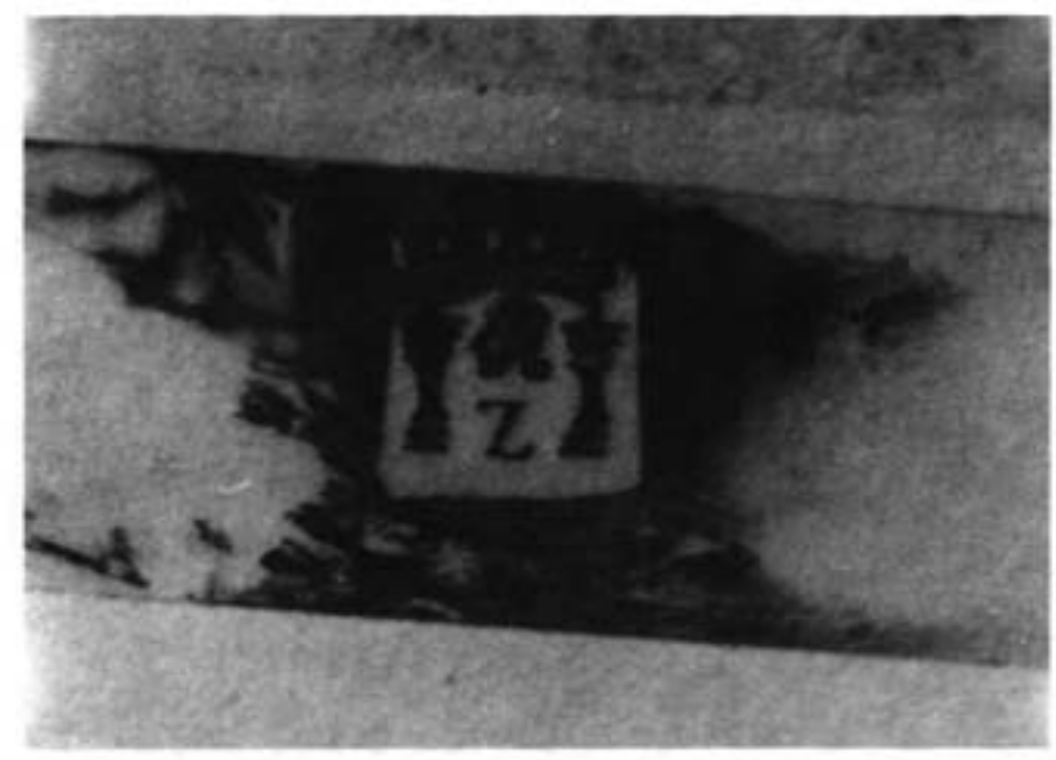

Figura 5 bis

Marca de la ciudad de Zacatecas estampada en las piezas de la iglesia parroquial de San Bartolome de Carmona (Sevilla) 